\title{
The impact of social isolation on a selected group of older brazilians within the context of the covid-19 pandemic
}

\begin{abstract}
Objective: This paper is an examination of the experiences of a selected group of older Brazilians people which aims to analyse how they have been impacted by COVID-19 and, particularly, how they have been affected by protective social isolation measures.

Methodology: 42 older residents of Sao Jose do Rio Preto were interviewed by phone. The applied script question was developed by International Longevity Centre the Netherlands, based at the Leyden Academy on Vitality and Aging. The data collection instrument consisted of five categories of analysis: social activities, social contacts and connectivity, well-being, vitality and health, and COVID-19 news and reports.

Results: All in-person social activity ceased with the implementation of the isolation measures. Most of the interviewees pointed out to be suffering do to absence of their children, grand-children, other relatives and close friends from whom they have being apart since the beginning of the Corona virus pandemic. A large number of the interviewees recognized a worsening of their health condition and attributed it to the suspension of the physical activities and the social life that they had before isolation.

Conclusion: The interviewed showed some insight about the experiences of older Brazilian adults during the COVID-19 pandemic. They all revealed a strong awareness of their physical vulnerability regarding corona virus. Most accepted the need to protect themselves through isolation or any other measures. However, there are barriers that difficulty the elderly people isolation as they live with of member of the family with different ages and in poor financial situations.
\end{abstract}

Keywords: coronavirus infections, social isolation, older people,quality of healthcare
Volume 6 Issue 3 - 2021

\author{
Natalia Sperli Geraldes Marin dos Santos \\ Sasaki,' Marília Louvison, ${ }^{2}$ Camila Garcel \\ Pancote, ${ }^{3}$ Maria de Lourdes Sperli Geraldes \\ Santos, ${ }^{4}$ Amena Alcântara Ferraz Cury, ${ }^{5}$ \\ Antonio Caldeira da Silva, ${ }^{6}$ Elisa Monteiro, ${ }^{7}$ \\ Alexandre Kalache ${ }^{8}$ \\ 'Union of Colleges of Grandes Lagos (Unilago), São José do Rio \\ Preto - SP, Brazil \\ ${ }^{2}$ School of Public Health - USP, São Paulo - SP, Brazil \\ ${ }^{3}$ Union of Colleges of Grandes Lagos (Unilago), São José do Rio \\ Preto - SP, Brazil \\ ${ }^{4}$ São José do Rio Preto Medical School (FAMERP), São José do \\ Rio Preto - SP, Brazil \\ 5Union of Colleges of Grandes Lagos (Unilago), São José do Rio \\ Preto - SP, Brazil \\ 'Union of Colleges of Grandes Lagos (Unilago), São José do Rio \\ Preto - SP, Brazil \\ ${ }^{7}$ ILC-BR, Rio de Janeiro - RJ, Brazil \\ \&ILC-BR, Rio de Janeiro - RJ, Brazil
}

Correspondence: Natalia Sperli Geraldes Marin dos Santos Sasaki, R. Dr. Eduardo Nielsem, 960 - Jardim Novo Aeroporto, São José do Rio Preto SP, I 5030-070, Brazil, Emailnsperli@gmail.com

Received: October 22, 202I | Published: November 05, 202 I

\section{Background}

Like most developing countries, Brazil is experiencing a rapid process of population ageing that requires innovative, targeted and affordable responses across multiple domains. ${ }^{1}$ It is clear that failing to decisively address these dramatic demographic transformations will result in much greater challenges for Brazil in the future. ${ }^{2}$ It is equally clear that there is an urgent need for the widespread implementation of sound, evidence-based public policies.

There are significant weaknesses in the current Brazilian public policy responses. The competition for scarce resources and recent cuts to budgets places enormous strains on the country's ability to respond to the needs of all ages, including elderly people. As in other countries, rather than being celebrated as a social triumph and opportunity, population ageing in Brazil is still framed as burdensome, costly and generationally divisive. In addition, there is a crisis in social protection policies in the country and the State that has not fully embraced its responsibilities towards the dependent older people as part of a wider poverty reduction strategy. ${ }^{3}$

The COVID-19 pandemic has further exposed the weaknesses of the existing health and social systems in Brazil. It has compounded the need for a comprehensive active/healthy ageing national strategy that includes a particular emphasis on the most socio-economically vulnerable and their difficulties in accessing public services. ${ }^{4}$ Prior to the pandemic, older Brazilians already faced a number of imposed limitations and specific barriers in accessing health services. The Corona virus crisis and the social isolation measures that have accompanied it have further increased inequity and marginalization, particularly among those who live alone and depend on others for support. ${ }^{5,6}$ Population ageing already resented significant challenges for public policies in Brazil. The pandemic exposed the faulty lines more fully and created an even greater sense of urgency.

\section{Introduction}

This paper is an examination of the experiences of a selected group of older Brazilians which aims to shed light on how they have been impacted by COVID-19 and, particularly, how they have been affected by protective social isolation measures. This is a descriptive study with a qualitative approach carried out in the city of São José do Rio Preto, in the north of the state of São Paulo. São José has an urban area of $160.734 \mathrm{~km}^{2}$ with an urbanization rate of $93.93 \%$. It has an estimated population of 447.924 inhabitants with an annual growth rate of $0.96 \% .^{7}$ Ranked in Group 1 of the State of São Paulo (elite group), with high relative wealth, longevity and education levels. ${ }^{8}$

Headquarters of the administrative region of São José do Rio Preto for 96 cities in the state of São Paulo, the main economic characteristic of the city is the provision of services and trade. It is a reference point for the wider northwestern region of the state - most notably, in the 
health sector. Due to its strategic location, connected to the North and South by BR153 (Transbrasiliana Highway), East (Porto de Santos) and West (Goiás and Mato Grosso), by the Washington Luiz, Euclides da Cunha and Feliciano Sales Cunha highways, the region offers access to expanding markets and traditional supply centers. ${ }^{8}$ It has a GDP per capita of R $\$ 37.720,07$, which represents $0.778 \%$ of the State's GDP. The water supply system covers $92.87 \%, 99.08 \%$ of sanitary sewerage and $99.94 \%$ of municipal waste pickup. ${ }^{7}$

The population-aging index in 2019 was $104.89 \%$ - the State being $78.13 \% .17 .25 \%$ of the population is aged 60 years and over, which is higher than the overall State proportion of 14.86 . It is estimated that in 2030 , the ageing rate will reach $118.10 \%$. With an aim to enhance public management and to facilitate planning actions in the territory, it was divided into 10 administrative regions (Bosque, Céu, Pinheirinho, Talhado, Cidade da Criança, Central, Represa, Vila Toninho, Schimitt and HB $)^{9}$ through decree 18.073-29/06/18. Central (26\%), Talhado (16\%), Vila Toninho (15\%), Schimitt (15\%) and HB (15\%) present higher proportions of older adults.Cidade da Criança (12\%), Pinheirinho (11\%"), Bosque (11\%) e Céu (7\%) present lower percentages.

As with other cities, São José do Rio Preto expanded horizontally from the Central Region and grew vertically from the 1950s. The pattern of urbanization was typical of most Brazilian cities-a sometimes haphazard proliferation of popular allotments on the periphery and an upward expansion in central zones. These popular allotments can be found in such zones as Pinheirinho, Céu and Bosque and tend to be marked by more negative socio-economic indicators. Some observers refer to "cities" within the city because of the great contrast between certain zones. ${ }^{9}$ Clandestine areas, often lacking infrastructure and quality of life, cohabit uncomfortably alongside the "legal" city with its regularized services, modern security apparatus and its residents with high purchasing power. Most of the latter are concentrated in the Represa and HB region. The Schimitt and Talhado districts of the city of Sao Jose do Rio Preto are characterized by rural features. Recently, these two regions have also been sites for housing estates, driven by the Housing Policy of the Minha Casa Minha Vida Program, which has increased the population concentration in these regions. In the last decades, as observed by Francisco (2011): "despite institutionalized urban planning, there has developed a disconnect between the zones primarily of production and the zones primarily of consumption, that has led to a fragmented and segregated city, from a socio-spatial point of view. ${ }^{10}$ To the north, the populous city; in the center-southwest vector, the upper classes; to the east and extreme southwest, the walled city of the wealthiest and, as if an add-on to the City, the illegal allotments of the excluded, in the outer periphery"

São José do Rio Preto has 76.636 people aged 60 or over, which is equivalent to $17.25 \%$ of the total population. ${ }^{7}$ Prior to the pandemic, a significant number of these older residents were already considered vulnerable or extremely vulnerable. These vulnerabilities can be examined from many different angles but all of them are strongly influenced by environmental variables - some more obvious than others. Brazil consistently ranks as one of the world's most unequal nations. ${ }^{11}$

As a strategy to reduce the speed of transmission of the new Corona virus and the number of deaths caused by it among the older population, social isolation, among other important measures, was imposed by the authorities. ${ }^{12}$ Clearly, social isolation measures in the face of a highly infectious virus can save thousands of lives, but it is also necessary to calculate both the short and long-term physical and emotional costs of that social isolation on the affected populations and to build mitigation into policy.,14 Social isolation affects individuals and groups in different ways, but, unsurprisingly, the most marginalized and the least economically favored are more likely to be damaged by it. ${ }^{5,6}$

\section{Methodology}

Telephone interviews with 42 older residents of Sao Jose do Rio Preto were carried out using a structured script developed by ILC Netherlands, based at the Leyden Academy on Vitality and Aging that was translated and adapted by ILC Brazil. ${ }^{14}$ An established relationship of trust and familiarity already existed as all the interviewees recently participated in surveys relating to the project "Age-friendly São José do Rio Preto" that was facilitated by ILC$\mathrm{BR}$. The individual interviews were recorded and transcribed and the nuclei of meaning were subsequently identified for the categorical thematic content analysis of qualitative data. The data collection instrument consisted of five categories of analysis: social activities, social contacts and connectivity, well-being, vitality and health, and COVID-19 news and reports. Prior to the interview, informed consent was taken orally, using a standardized script. The study was submitted to the Research Ethics Committee of the Union of Colleges of Grandes Lagos (Unilago), approved by the report: 3.429 .122 and CAAE: 16552319.0.0000.5489. The research on the impact of COVID-19was undertaken on an amendment, being approved by the report: 4.023.913 and CAAE: 16552319.0.0000.5489.

\section{Categories of analysis}

\section{Social activities}

Social and leisure activities may contribute to physical health and psychological well-being in older adults. ${ }^{3,15}$ For older adults, participation in social activities is clearly very important to support intellectual vigor, to create bonds and friendship networks that lead to a sense of community, and to promote closer intergenerational relationships that go beyond family. The concept of participation involves several dimensions such as intellectual, social, civic, recreational and spiritual, which makes the individual more empowered in terms of their representations in society ${ }^{14}$ and it is a foundational pillar for Active Ageing. ${ }^{15}$ For most of the interviewees, all in-person social activity ceased with the implementation of the isolation measures. Most suspended all group physical activity entirely.

"Ah, I used to do physical exercise at the sports health center, but now I'm not doing anything, I'm just thinking about work, because I'm a construction worker, so I'm working as usual...".

Among the interviewees were some older adults who had never been in the habit of practicing structured physical activity, either because they did not like it or because of such constraints as caring for other older adults. Most commonly, these caregivers were middleaged or older women, wives or daughters, who share a home with the receiver of care and who have little or no support for their role. ${ }^{16}$

"...I don't do any physical activity... because my husband is sick. I spend most of my time walking around the house and the backyard, because I live in a farm."

Some expressed that they tried to maintain a physical routine in their own homes but felt that it was difficult to sustain in the absence of guidance and company. Previously, many of the interviewees had regularly participated in the physical activities offered by the City Hall that took place in public squares and such other spaces as those 
attached to the Primary Health Care or local churches. Although there have been efforts by physical trainers to continue instruction on-line, many of the older interviewees lacked access to digital equipmenta common characteristic to countries with high levels of social inequality. ${ }^{5,11}$ Many of the older adults who have internet access or proficiency in using digital equipment stated that they attend online gym and other classes. By adding greater structure and intensity to their physical activity, the feelings of anguish that are so common to older persons in high COVID incidence countries, are reduced. ${ }^{17}$

"I used to do water aerobics and stretching. I don't do them anymore. I walk inside the house and in the backyard. I do a little stretching for about 20 minutes. I turn on the cell phone and follow the instructor doing it...".

The suspension of the bulk of activities that provided social interaction for the older interviewees, such as Mass and other church services, initiatives by Reference Center for Social Assistance and the senior citizens' balls held at the Elderly Living Center, created a sense of loss and discernible feelings of sadness and loneliness.

"... I used to go to four senior citizens groups. We were a group of 10 friends and two couples. We used to do trips together and have coffee at each other's homes. To get locked up like this...Sometimes I feel desperate ...".

“... I don't even know when we are going to dance again. They took the best things from us....I think that I will not be able to go back at least until the end of the year. It will be difficult for us older folks for a long time to come, won 't it?...".

The domestic routine for many of the interviewees did not suffer major changes except for the fact that they no longer went shopping a task that was delegated to their children or younger relatives. Many reported enormous dissatisfaction at not being able to go to the market or to the bakery, a daily routine that had given them pleasure. Others continued to perform shopping tasks despite being aware of the risks simply because they had no alternative.

"Before, we used to go out, go to the market, go for a walk, now we don't go out, right?...out of fear...my son goes for us....".

"We are getting mouldy at home...I don't go out. Sebastiã o(husband) does go out to buy some things but only because there is no one else to go. But he is quick. He comes back fast. Mostly, we are at home all the time...".

The impact of social isolation seems to be less felt by those older interviewees who either live in rural settings or have access to rural land in more peripheral regions of the city.

"I have a rural property...I go there every other day. On the other days, I just stay inside my house. I don't spend any time on the street...".

“...I'm great, thank God ... I live on a farm and I'm using this opportunity to really take care of it, since I can't leave it. I'm using the time to concentrate purely on my immediate environment...".

A small number of the older interviewees had taken this time as an opportunity to learn "new things" such as manual activities, developing reading habits, improving their connection with digital tools for communication, among others.

"I am a Jehovah's Witnesses and I keep in touch with my Church by videoconference...it helps me a lot!”.

"...my granddaughter bought some dish towels and told me to spend some time crocheting...so I'm learning to do it...".

\section{Social contacts and connectivity}

Clearly, social interaction is important for human beings at all stages of life. Elderly people with access to social network shave better physical and mental health conditions. ${ }^{4,18}$ Social isolation was negatively associated with health conditions. ${ }^{13,17,19}$ Many of the interviewees felt great suffering from the absence of their children, grand-children, other relatives and close friends from whom they have being apart since the beginning of the Corona virus pandemic.

“...I particularly miss seeing my brother, my children, my grandchildren, my daughter-in-law ... and others. We need to see each other. We are not meant to be always alone. We cannot live in isolation, that's the truth!".

"...They (children and grandchildren) used to come to see me from afar, right?...but from a long way away. We would kiss and hug. Now, I don't see the ones that live close, let alone the ones who live far away. It is very sad, isn't it?

The previously and more socially active interviewees who had given up their senior citizen groups and other activities because of the pandemic, expressed particularly strong feelings of loss, as well as enormous anxiety about the future. Unsurprisingly, those with digital literacy and internet access felt that their ability to routinely keep in contact with family and friends helped them to mitigate their feelings of isolation and loneliness.

“...I used to go to the Kingdom Hall every Wednesday and Saturday. We would talk, hug, greet the brothers...Now, we only communicate using Zoom".

"...now, thank God, with the internet we talk whenever we want... so things are manageable...

One of the most striking and disturbing features of Brazil is its enormous social inequality,11 a characteristic that São José do Rio Preto shares. It is clear from the interviewee responses that the imposed isolation measures impact differently across the socioeconomic range.

"...I don't even have a phone, so I can't call anyone. When I need to talk to relatives, my daughter calls them. When they call me, it's on her cell phone...".

The role of the family in the life of many older Brazilians remains very important, but, as in other countries, contemporary family relationships have become more complex. Even before the pandemic, the culture of family care was increasingly being challenged by a dwindling pool of family care-givers alongside changing expectations. Many older Brazilians were already impacted by what can be termed "family insufficiency". ${ }^{14}$ For many of those older Brazilians who lacked support prior to the pandemic, their domestic routine under imposed isolation has not substantially changed.

“...You see, I have a son, a daughter, a grandson and a granddaughter...They don't come here, I don't go there... My relatives are all friends, but it is not like we visit each other... this is my life... I go on living it... There is only my neighbor here and we chat, he over there and I over here...".

\section{Well-being}

Social isolation and social distancing in the context of COVID-19 can undoubtedly save the lives of millions of older people with varying degrees of vulnerability, but it must also be recognized that the same measures can adversely affect well-being and negatively impact the process of ageing and longevity. ${ }^{19}$ Personal resilience is 
influenced both by the environment and the network of relationships, such as family and friends.

“... We feel very depressed with these problems, right? It is like being inside a prison. I have never been inside one, but I assume it is the same...".

The inactivity experienced by older people during the isolation period has been associated with increased anxiety and the greater appearance of neurological and vascular diseases. Studies indicate an increased incidence of more premature deaths in individuals over 75 years of age. ${ }^{20,21}$

“... I'm feeling very depressed, really... I have this anxiety... I feel like I'm going to die....”.

"... It makes me anxious....not knowing what the future is.... if life will ever return....".

Many older people throughout the world have been negatively compromised during the pandemic, but the situation is particularly acute in Brazil with its very high infection numbers, pervasive substandard housing conditions, strained infrastructures and confused political messaging. ${ }^{20,22}$ The majority of the interviewees felt that both their autonomy and their independence had been severely compromised during their social isolation.

Many of them sought help from third parties to perform roles that were previously undertaken by themselves, such as shopping, paying bills, and participating in leisure activities- whether with the family or in the company of friends.

"... I am a calm person... but due to this social isolation we get kind of stressed out... I feel it in my skin, you see. It starts to itch...".

“... I am staying at home. It is terrible. I used to go to the evangelical church, I used to go shopping... I went everywhere, but now I am locked up because of this corona virus...".

For those interviewees, who for reasons of incapacity or choice were already in the habit of staying at home most of the time, their routine did not change significantly to the point of compromising their well-being. For this group, contact with family members tended to be greater and this contact remained quite strong even after the isolation measures adopted by the city. Predictably, financial security was regarded as a key indicator of comfort level.

"... I am fine, thank God, because happiness is in the family, right? So, as my children get along well, and thank God they are working... I am $\operatorname{good} \ldots .$.

“... Ah, I am really good... I live in a cool apartment, nice, big, with my family... so I am happy...”.

Despite the fears arising out of the political, economic and health crisis, many interviewees expressed their belief that all this was temporary and they were spending time thinking about their future beyond the pandemic.

"First thing I will do when the isolation is over... I will visit my mother... I miss her a lot...".

“... when all this is over, I will go to the church to thank...”.

"Holy Mary, my friend, I want to see my girlfriends, I want to go out, visit them, hug... we are going to party, we are going to play cards, travel...".

"There's something that I really wish to do... for ten years I've been trying to build a house for me to live in and stop paying rent, and it's at the slab level, but my payment stopped I stopped... So the only desire I have is to cover it for me to stay inside...".

\section{Vitality and health}

In addition to health services, security, housing, food, social justice, equity and a friendly environment are important dimensions for the health and vitality of older people..$^{23}$ It is one of the four key pillars of the Active Ageing model. ${ }^{24}$

Alongside the physical and social limitations imposed by isolation measures, the fears and uncertainties experienced by older individuals during the pandemic can negatively influence their health. ${ }^{15}$ This can vary widely according to different economic and psycho-social settings. ${ }^{21}$

A large number of the interviewees recognized a worsening of their health status and attributed it to the suspension of the physical activities and the social life that they had enjoyed before their isolation. There is indication that an increase in alcohol consumption, the use of psychotropic drugs, domestic violence and suicide has an association with social isolation. ${ }^{20}$

Some interviewees reported that although they were doing physical exercise at home, it was not with the previous intensity and frequency. They felt that they were already feeling the negative health consequences of their more sedentary habits.

"I really miss doing physical exercise... I used to feel good and now my blood pressure has risen because I am sedentary...”.

"... I had to stop doing exercises due to the pandemic. Because of that I have started to feel pain again..." (statement of a 73-year-old resident of the central area).

"... we walk around the house, so we don't get sedentary... but it's not the same thing...".

"I walk... around the block... I have to do this because I can't stay here all the time...".

Others felt that it was their feelings of loneliness and sadness that were responsible for their negative physical and mental health outcomes in this period - a conclusion more common among women than men. ${ }^{17,21}$

"My health seems good... I feel good, despite the stress... physically I feel good, you know? But there is that sadness, it gets bad inside, you see."

Some reported that although they have health concerns, they are afraid to go to places of treatment because of the risk of infection.

"I was not going out but now it (my symptoms) has gotten worse... I have an appointment at the specialty kidney clinic, right? Because I'm peeing blood... but I'm waiting for this pandemic to end...".

Economic deterioration is creating additional pressure for older Brazilians as well as their families and their communities. In the context of the pandemic, continued labor force participation by older workers has become more hazardous. Higher unemployment also among the young means less available financial support from children. In some cases, it means that meager old age pension income is now shared across the family and decisions about spending priorities are sometimes made that are detrimental to the health of the older family member.

“... I have a bone problem ... I did the exams with a rheumatologist... I have to wait for them to call. Once she has seen the exam results, 
she will give a treatment... But then I keep thinking... "My God, the medicine she gives they don't have it in the clinic, I have to buy it and it is expensive... Now I don't know what I'm going to do...".

\section{COVID-19 news and reports}

A large proportion of the $6.9 \%$ of the Brazilian population that is illiterate are older people. Added to this is a high degree of scientific illiteracy across all age groups and social classes. In many cases, this reality has led to confused interpretations of public health messages. ${ }^{11}$ Responses to the pandemic in Brazil became politicized at a very early stage. Populist, non-evidence-based narratives, sometimes officially endorsed, have circulated freely and there has been a push-back to restrictive practices such as social isolation. There has been little in the way of a consistent national messaging or strategy.

Most of the interviewees, however, recognize the importance of social isolation and other preventative measures, but were exhausted by the news related to the pandemic. Many reported intense feelings of imminent danger due to the negativity of the reports. Many made a conscious decision to ration or to no longer follow the news at all. Those with a higher level of education, arguably more invested in their own health actions, tended to have a greater sense of anguish. ${ }^{17}$

"Actually, I don't follow it much. There are times when we get a little doubtful about certain things, so I prefer to avoid it a little...".

"In the government there is a lot of corruption, a lot of thieves, and some news that I like to watch says that they are just using this virus and spending people's money... It makes me very sad....".

In common with some younger Brazilians, some older Brazilians are mistrustful of the mainstream narratives surrounding COVID-19. Some are reluctant to believe in the pandemic at all and attribute the current state of affairs to the political crisis that the country has faced over the past few years.

“.... joke a lot with people.... and now we can't even do that anymore because of this pandemic they invented. This is all politics....".

Although most of the interviewees felt that social isolation measures have been shown to reduce the transmission of the disease, many also had concerns about the need to work and the financial future of the country.

"I agree with some things, such as wearing masks, the over-60s and those with co-morbidities staying at home. But those who are not at risk can still go to work. They can work so that the country doesn't shut down. Not to stop the economy...".

"... I think that the authorities that analyze health should not leave everyone standing the way they are, because in a few days they will die of COVID and people will starve, too, because the government helps two months and then it doesn't help anymore. I haven 't managed to get the government assistance myself yet...".

"I used to watch it (the television news), but I stopped because if you start to look at all those round balls (graphical representations of deaths) you begin having shortness of breath..."

Reports about the over-loading of the public health system, on which $83 \%$ of older Brazilians rely (mainly Afro-Brazilians), has added to the feelings of fear. ${ }^{11}$ For many, this anxiety builds on pre-existing concerns about the health system brought about by the budgetary cuts of recent years and ageist institutional barriers and practices. ${ }^{4}$ There is a thought shared by many older people that hospitalization from corona virus infection often means a solitary death.
"We get scared... I think there should be another way of treatment, because when the elderly go to the hospital, they usually don't come back, they can't see their family anymore and this is very sad. Imagine our situation...".

All the interviewees were aware of their greater vulnerability. There is widespread recognition of the dangers presented by such co-morbidities as diabetes, hypertension and obesity along with cardiovascular and respiratory diseases. ${ }^{17}$ The fact that the number of deaths is $30 \%$ higher among those above 60 yearsold $^{11}$, is a characteristic also observed here in the city of São José do Rio Preto.

"In this case, we worry, because the elderly has less energy and deserve special care in terms of food and hygiene, I think in that sense...".

"I'm taking care of myself, I don't leave the house, I have hand sanitizer and I really wash my hands with detergent...".

\section{Conclusion}

Clearly, it will take many years to fully assess the impacts of the COVID-19 social isolation measures on the lives of older people and their communities. As elsewhere, the Brazilian elderly population is not homogenous. Their inter-personal and domestic situations vary greatly and respond to circumstances indifferent ways. The socioeconomic divides are very wide in Brazil and every investigation must be conducted through the lens of inequality. In addition, as you would expect in such an enormous country, the cultural and regional range is vast so it is important to be wary of extrapolations. Unsurprisingly, some individuals and communities are far more resilient than others. Developing resilience ${ }^{25}$ is essential to face periods of crisis, such as the one experienced in the pandemic.

Those interviewed in this small study, however, offer some insight into the experiences of older Brazilian adults during the COVID-19 pandemic. They all revealed an acute awareness of their physical vulnerability to the corona virus. Most accepted the need to protect themselves through isolation and other measures, even if the practice is difficult for those in cramped multi-generational households and densely populated communities or with financial insecurity. Many were found to cope relatively well with their new-found circumstances, but nearly all expressed varying degrees of emotional hardship related to their reduced social contact -from occasional sadness to debilitating depression. Some level of anxiety was a constant companion for most of the interviewees. Only some of that anxiety was about contracting the corona virus. For many, their anxiety was related to the collapse of the public health system and the fear that general medical treatments became more difficult to access. For others, their own and their family's financial insecurity was a bigger concern. Most reported an increase in sedentary habits and reduced incentive for physical exercise. Many found much of the public discussion about the corona virus exhausting and some expressed deep cynicism about much of the received information. Despite their isolation, many of them remained key anchors within their families, even at a distance - providing emotional reassurance and sometimes financial support. Older people may be more vulnerable in extreme circumstances, but there is evidence to suggest that they are also key to recovery.

\section{Acknowledgments}

None.

\section{References}

1. Kalache A. O mundo envelhece: é imperativo criar um pacto de solidariedade social. Ciênc Saúde Coletiva. 2008;13(4):1107-1111. 
2. Miranda GMD, Mendes ACG, Silva ALA. O envelhecimento populaciona brasileiro: desafios e consequências sociais atuais e futuras. Rev bras geriatr gerontol. 2016;19(3):507-519.

3. Alcantara AO, Camarano AM, Giacomin KC. Política nacional do idoso: velhas e novas questões. Instituto de Pesquisa Econômica Aplicada. 2016

4. Kalache A, Silva A, Giacomin KC, et al. Envelhecimento e desigualdades: políticas de proteção social aos idosos em função da Pandemia Covid-19 no Brasil. Rev bras geriatr gerontol.2020;23(6):e200122.

5. Lloyd-Sherlock PR, Ebrahim S, Geffen L, et al. Bearing the Brunt of COVID-19: older people in low and middle income countries. BrMed J. 2020;368:1-2.

6. Tesch-Römer C, Lamura G. Older adults in the first wave of the Corona pandemic. European Journal of Ageing. 2021.

7. São Paulo, Fundação Sistema Estadual de Análise de dados/Fundação SEADE. Informações do Município São José do Rio Preto. 2021

8. São José do Rio Preto (SP). Secretaria Municipal de Planejamento Estratégico, Ciência, Tecnologia e Inovação. Conjuntura Econômica de São José do Rio Preto. 2019, 34.ed.

9. São José do Rio Preto (SP). Decreto No 18.073, DE 29 DE JUNHO DE. Institui a Divisão Geográfica da área do Município de São José do Rio Preto em Regiões e dá outras providências. 2018.

10. Francisco AM. Contribuição à história da urbanização de São José do Rio Preto-SP. Revista Topos. 2011;5(1):119-142.

11. Ribeiro F, Leist. Who is going to pay the price of Covid-19? Reflections about an unequal Brazil. International Journal for Equity in Health. 2020;19(91).

12. Walker GT, Whittaker C, Watson O, et al. The Global impact of COVID-19 and strategies for mitigation and suppression. Imperial College London. 2020;1-18.

13. Heymann D. The Elderly and the COVID 19 Crisis: A Chronicle of Deaths Foretold, in Isolation and Total Indifference. Frontiers in Public Health. 2021;08:1-3.
14. ILC-BR Active Ageing: A Policy Framework in Response to the Longevity Revolution. International Longevity Centre-Brazil Publications. 2015.

15. Kano M, Rosenberg P, Dalton S. A Global Pilot Study of Age-Friendly City Indicators Social Indicators. Research. 2018;138(3):1205-1227.

16. Santos-Orlandi et al. Perfil de idosos que cuidam de outros idosos em contexto de alta vulnerabilidade social. Esc Anna Nery. 2017, 21(1).

17. Qiu J, Shen B, Zhao M, et al. A Nationwide Survey of Psychological Distress among Chinese People in the COVID-19 Epidemic: implications and policy recommendations. General Psychiatry. 2020;33.

18. Holt-Lunstad J, Smith TB, Baker M, et al. Loneliness and Social Isolation as Risk Factors for Mortality: A Meta-Analytic Review. Perspective on Psycological Science. 2015;10(2):227-237.

19. Briguglio M, Giorgino R, Dell'Osso B, et al. Consequences for the Elderly After COVID-19 Isolation: FEaR (Frail Elderly amid Restrictions). Frontiers Psycology. 2020, 11: 1-5.

20. Otu A, Charles CH, Yaya S. Mental Health and Psychosocial Well-being during the COVID-19 Pandemic: the invisible elephant in the room. Int J. Ment Health Syst. 2020;14(38).

21. Serafini G, Parmigiani B, Amerio A, et al. The psychological impact of COVID-19 on the mental health in the general population. QJM. 2020;13(8):531-537.

22. Plagg B, Engl A, Piccoliori G, et al. Prolonged Social Isolation of the Elderly during COVID-19: Between benefit and damage. Archives of Gerontology and Geriatrics. 2020;89.

23. WHO Ottawa Charter For Health Promotion, World Health Organisation Publications, First International Conference on Health Promotion, Ottawa. 1986.

24. Barros MBA, Goldbaum M. Desafios do envelhecimento em contexto de desigualdade social. Rev SaudePublica. 2018;52(2):1s-3s.

25. ILC-BR. Building Resilience Throughout Our Increasingly Longer Lives. International Longevity Centre-Brazil Publications. 2017. 